\title{
Histological changes in mice tissues induced by gold nanoparticles with different surface coatings and sizes
}

\author{
Ilyas Ozcicek, 1, 2, Nilufer Ulas Ayturk ${ }^{3}$ (D) Nese Aysit ${ }^{1,2}$ \\ ${ }^{I}$ Department of Medical Biology, School of Medicine, Istanbul Medipol University, Istanbul, Turkey \\ ${ }^{2}$ Health Science and Technologies Research Institute (SABITA), Istanbul Medipol University, Istanbul, Turkey \\ ${ }^{3}$ Department of Histology and Embryology, Faculty of Medicine, Çanakkale Onsekiz Mart University, Canakkale, Turkey
}

\section{ABS TRA C T}

Aim: Gold nanoparticles (AuNPs) have many biomedical applications due to their unique properties (e.g., chemical stability, optical properties, biocompatibility, easy synthesizability, and multiple functionalizations). This study aimed to synthesize two highly monodispersed and stable AuNPs of different sizes ( $\mathrm{AuNP}_{20}$ and $\mathrm{AuNP}_{50}$ ), modified with polyethyleneimine (PEI) and polyethylene glycol (PEG), and systematically investigate their toxicological effects on histological changes in the organs of BALB/c mice.

Methods: AuNPs $\left(\mathrm{AuNP}_{20}\right.$ and $\left.\mathrm{AuNP}_{50}\right)$ were synthesized, and their surfaces were coated with PEI and PEG. All necessary characterizations were performed. After the application of two different doses of intravenous injections (IV) of the AuNPs (0.5 and $5 \mathrm{mg} \mathrm{Au} / \mathrm{kg}$ ), their toxicological effects and histological changes in the various mice organs (e.g., liver, spleen, kidney, brain) were evaluated with multiple parameters $48 \mathrm{~h}$ post injection. Fourteen days after a single high dose ( $5 \mathrm{mg} \mathrm{Au} / \mathrm{kg}$ ) IV injection of AuNPs, transmission electron microscopy (TEM) analysis was performed to reveal their ultrastructural effects in the liver of the mice.

Results: Stable and highly monodispersed AuNPs were synthesized successfully. Since the liver is the most critical organ in nanotoxicological evaluations, changes in the parameters of AuNPs were shown to have remarkable effects. Although there were no differences in the impact caused between the two AuNPs sizes, the microstructure of the liver tissue treated with AuNP nanoparticles with PEI or PEG coatings was similar to that observed in the control group. Microstructural histological changes in the other organs (e.g., brain, kidney, and spleen) were relatively less than those found in the liver. The PEI and PEG surface coatings generally increased the biocompatibility of the AuNPs. According to the TEM analysis data, apparent cellular changes were observed after a long exposure period in the AuNP groups without an additional surface coating. Although slight cellular alterations were observed in the AuNP groups coated with PEG and PEI, the morphology of the hepatocyte cells was generally healthy.

Conclusion: The surface coating of the AuNPs was a more decisive parameter than the size of the nanoparticles in terms of in vivo histological toxicity. The stability, biocompatibility, and surface coating of the AuNPs were critical parameters for potential nanoteranostic applications.

Key words: Gold nanoparticles, nanotoxicity, histopathology, polyethyleneimine, polyethylene glycol, surface functionalization, mice.

Ilyas Ozcicek

Department of Medical Biology, School of Medicine, Istanbul Medipol University, Istanbul, Turkey

Health Science and Technologies Research Institute (SABITA), Istanbul Medipol University, Istanbul, Turkey
E-mail: iozcicek@medipol.edu.tr ilyasozcicek@gmail.com

Received: 2021-08-05/Revisions: 2021-11-04

Accepted: 2021-11-30/Published online: 2022-01-01 


\section{Introduction}

Gold nanoparticles (AuNPs) have many biomedical applications due to their unique chemical, physical, and optical properties [1]. Nanocarrier systems have many advantages, such as a large surface area, multiple functionalization, and small sizes [2]. Because of these superior features, AuNPs have been widely preferred in biomedical research recently, with applications that include detection [3], biosensors [4], bio-imaging [5], photothermal therapy [6], drug delivery [7], and DNA or RNA delivery [8, 9]. Also, to the beneficial effects of nanomaterials, there is a critical need to investigate the potentially toxic effects of AuNPs in biological environments. The synthesis method, size, surface functionalization, biological exposure time, and concentration of nanoparticles are fundamental parameters in nanotoxicological evaluations [10].

In some cellular biology studies in which AuNPs were used without additional surface coating, the researchers showed that the nanoparticles often accumulated in larger endosomes as aggregates. Although these particles have primarily been evaluated as biocompatible in terms of cellular toxicity, small ones have been reported to reduce cellular viability [11-13]. On the other hand, in some cellular biology studies in which PEG-modified AuNPs were used, the authors observed that the particles were localized in smaller endosomes, with consequent aggregation minimization and increased particle uptake [14-16]. Again, PEI modification of AuNPs has been shown to increase the stability, biocompatibility, and cellular uptake of nanoparticles [17]. Previously, some in vivo studies have been conducted to evaluate the toxicity and histological effects of various AuNPs. Researchers have reported that smaller nanoparticles cause more in vivo toxic effects, such as the swelling of hepatocyte cells [18]. Different PEG-coated AuNPs have been shown to reduce toxicity and increase stabilization and circulation time in the blood [19]. However, further in vivo studies are needed to determine the histological effects of the different AuNPs and their role in nanotoxicity.

This study aimed to synthesize two highly monodispersed and stable AuNPs of different sizes $\left(\mathrm{AuNP}_{20}\right.$ and $\left.\mathrm{AuNP}_{50}\right)$ and modified with polyethyleneimine (PEI) and polyethylene glycol (PEG). Additionally, this study aimed to systematically investigate their toxicological effects on histological changes in the organs of $\mathrm{BALB} / \mathrm{c}$ mice.

\section{Materials and methods}

\section{AuNP synthesis, surface functionalization, and characterization}

First, seed AuNPs $\left(\mathrm{AuNP}_{20}\right)$ were synthesized and then used to synthesize AuNPs of average size $\left(\mathrm{AuNP}_{50}\right)$. For the production of $\mathrm{AuNP}_{20}$, a modified Turkevich synthesis method was used [20]. After $100 \mathrm{ml}, 0.25 \mathrm{mM}$ of chloroauric acid $\left(\mathrm{H}\left[\mathrm{AuCl}_{4}\right]\right)$ solution (Sigma-Aldrich) was prepared, and trisodium citrate dihydrate (Sigma-Aldrich Corp.) was added at a concentration of $0.033 \%$ by increasing the rotational speed of the boiling solution. After the prepared seed AuNP solution was cooled, it was centrifuged (Thermo-Scientific, MicroCL 21R) at $7,000 \mathrm{~g}$ for $30 \mathrm{~min}$. Then, it was dispersed in deionized water. Average-sized AuNPs $\left(\mathrm{AuNP}_{50}\right)$ were synthesized using the seeding-growth method [21]. After $100 \mathrm{ml}$, $0.25 \mathrm{mM}$ chloroauric acid solution was prepared, and $2.4 \mathrm{ml}$ of seed AuNPs were added and mixed. Trisodium citrate was added in the next step at a concentration of $0.15 \mathrm{mM}$, and 1 $\mathrm{ml}$ of $25 \mathrm{mM}$ hydroquinone (Sigma-Aldrich Corp.) solution was added and mixed for 10 
min. Then, the synthesized average-sized AuNPs (AuNP 50$)$ were centrifuged at 7,000 g for $30 \mathrm{~min}$ and dispersed in deionized water. For the PEI functionalization of all the synthesized AuNPs, a 2\% PEI (Mw: 10,00025,000, Sigma-Aldrich Corp.) stock solution was prepared. Then, it was added to the AuNPs solutions at a $0.005 \%$ final concentration and mixed [17]. After the PEI coating process, all the AuNPs solutions were centrifuged at 7,000 $\mathrm{g}$ for $30 \mathrm{~min}$ and then dispersed in deionized water. A $0.15 \mathrm{mM}$ PEG-SH (Mw: 5,000, Nanocs) solution was prepared for PEG functionalization of all the synthesized AuNPs. Then, $100 \mu$ of the solution was added to each ml of the synthesized AuNPs solution and mixed. After the PEG coating, all the AuNPs solutions were centrifuged at 7,000 $\mathrm{g}$ for $30 \mathrm{~min}$ and then dispersed in deionized water.

Inductively coupled plasma mass spectrometry (ICP-MS) measurements were applied (Perkin Elmer ICP-MS, Nexion 300X) to precisely quantify the amount of gold (Au) in all the synthesized AuNPs solutions. All AuNPs solutions were standardized to contain $\mathrm{Au}$ at 50 $\mu \mathrm{g} \mathrm{ml}^{-1}$ and $500 \mu \mathrm{g} \mathrm{ml}^{-1}$ for subsequent animal studies. The synthesized AuNPs were characterized regarding zeta potential and size using a zeta sizer (Zetasizer Ultra-Malvern). The surface plasmon resonance (SPR) spectrum shifts were determined using a UV-visible spectrophotometer (Shimadzu UV-1800). Scanning electron microscope (SEM) images of the AuNPs were taken (SEM-Zeiss Geminisem 500).

\section{Animals}

A total of 27 male adult BALB/c mice were used for histological staining $(\mathrm{n}=18)$ and transmission electron microscopy (TEM) studies $(n=9)$. The animal procedures were performed under the Istanbul Medipol
University Institutional Animal Care and Use Committee (IMU-HADYEK, Approval date/number: May 18, 2017/21). For histological staining, the AuNPs were dissolved in $250 \mu \mathrm{l}$ of sterile PBS (Sigma-Aldrich Corp.) and injected in two different doses (0.5 and 5 $\mathrm{mg} \mathrm{Au} / \mathrm{kg}$ ) from the tail veins of the mice. In contrast, all the AuNP groups were dissolved in $250 \mu \mathrm{l}$ of sterile PBS again and injected as a single dose $(5 \mathrm{mg} \mathrm{Au} / \mathrm{kg})$ from the tail vein of the mice for liver TEM studies. All mice were allowed free access to drinking water and diet. The cages were located in temperaturecontrolled normal room conditions and a lightdark period of $12 \mathrm{~h}$.

\section{General histological studies}

Hematoxylin and eosin (H\&E) staining was performed to evaluate the general toxicological effects of the various AuNPs groups on the histological changes in the mice organs (e.g., liver, spleen, kidney, brain). All the necessary organs were collected from the mice $48 \mathrm{~h}$ post injection and fixed in $10 \%$ formalin solution (Tekkim) to evaluate the toxicity of the AuNP groups. The tissues were kept at $60^{\circ} \mathrm{C}$ in increasing ethanol (Sigma-Aldrich Corp.) series (from 70-100\%) for the dehydration process. Then, the transparency process was applied with two xylene (Tekkim) exchanges. The tissues were left at room temperature for 1 $\mathrm{h}$. In the final step, all the tissue samples were embedded in paraffin (Tekkim) blocks, sectioned into $5 \mu \mathrm{m}$ slices, and stained with $\mathrm{H} \& \mathrm{E}$ (Bio-Optica) for histological examinations.

\section{TEM analysis of liver tissue}

TEM analysis was conducted to reveal the toxicological effects of different AuNPs groups on the ultrastructural changes in the liver of the mice in more detail. All liver tissue samples 
were collected from the mice 14 days post injection. The tissues were rapidly dissected and separated. A total of $1 \mathrm{ml}$ of $2.5 \%$ glutaraldehyde (Sigma-Aldrich Corp.) was added to the tissue samples, and the fixation procedure was applied in the ice for $4 \mathrm{~h}$. Glutaraldehyde was discarded after the fixation process, and washing steps were applied three times using sodium cacodylate trihydrate buffer (Sigma-Aldrich Corp.). Then, the tissue samples were post-fixed with $1 \% \mathrm{OsO}_{4}$ (EMS) for $1 \mathrm{~h}$. The samples were treated with an increasing acetone series (from 10-100\%) for 5 min following the buffer-washing steps. The tissue samples were then embedded using an Epoxy-Embedding Kit (Sigma-Aldrich) and kept for $24 \mathrm{~h}$ at $60^{\circ} \mathrm{C}$. Ultrathin sections (50-60 $\mathrm{nm}$ thick) were taken from the liver tissue samples (Ultramicrotome-Leica EM FC7) and placed on copper TEM grids (EMS) for imaging and histological examinations in the final step.

\section{Results}

\section{AuNP characterization}

The main characteristic properties of the synthesized AuNP groups are shown in Table 1. Highly monodispersed and stable AuNPs were synthesized using the modified Turkevich synthesis method and the seeding-growth method. The size of the AuNPs increased depending on the PEI and PEG coatings. Again, the polydispersity index (PDI) values remained below 0.2 , with a high monodispersed level. It was shown with these results that a highly controlled and optimized protocol was applied. The changes in UV-visible peaks depended on the surface coatings for the seed- and mediumsized AuNPs. After PEI functionalization, there was a significant positive increase in zeta potentials. On the other hand, the zeta potential values remained negative after PEG modification. The synthesis of highly monodispersed and stable AuNPs was confirmed according to the SEM images shown in Figure 1. The PEI and PEG surface coatings were visible for all surface-modified AuNP groups. Additionally, the size measurements of the AuNPs were verified based on the SEM images.

\section{General histological evaluations}

$H \& E$ staining was performed to evaluate the general toxicological effects of different AuNPs groups in the mice organs (e.g., liver, brain, kidney, spleen) after $48 \mathrm{~h}$ post injection. All AuNP groups were administered to mice in two different doses $(0.5$ and $5 \mathrm{mg} \mathrm{Au} / \mathrm{kg}$ animal weight) within the scope of general histological

Table 1. Main characteristic properties of synthesized gold nanoparticle groups.

\begin{tabular}{|c|c|c|c|c|}
\hline AuNP Groups & $\begin{array}{l}\text { Hydrodynamic } \\
\text { diameter (nm) }\end{array}$ & $\begin{array}{l}\text { Polydispersity } \\
\text { index (PDI) }\end{array}$ & $\begin{array}{c}\text { UV-visible peak } \\
\text { (nm) }\end{array}$ & $\begin{array}{c}\text { Zeta potential } \\
(\mathrm{mV})\end{array}$ \\
\hline $\mathrm{AuNP}_{20} \mathbf{a}^{\mathbf{a}}$ & $20.07 \pm 0.15$ & 0.12 & 520 & -49.55 \\
\hline $\mathrm{AuNP}_{23}-\mathrm{PEI}$ & $23.45 \pm 0.20$ & 0.16 & 522 & +32.20 \\
\hline $\mathrm{AuNP}_{24}-\mathrm{PEG}$ & $24.82 \pm 0.30$ & 0.18 & 523 & -21.75 \\
\hline $\mathrm{AuNP}_{50}$ & $50.64 \pm 0.16$ & 0.13 & 534 & -36.16 \\
\hline $\mathrm{AuNP}_{54}$-PEI & $54.22 \pm 0.20$ & 0.17 & 536 & +29.15 \\
\hline $\mathrm{AuNP}_{56}$-PEG & $56.45 \pm 0.30$ & 0.19 & 538 & -31.15 \\
\hline
\end{tabular}



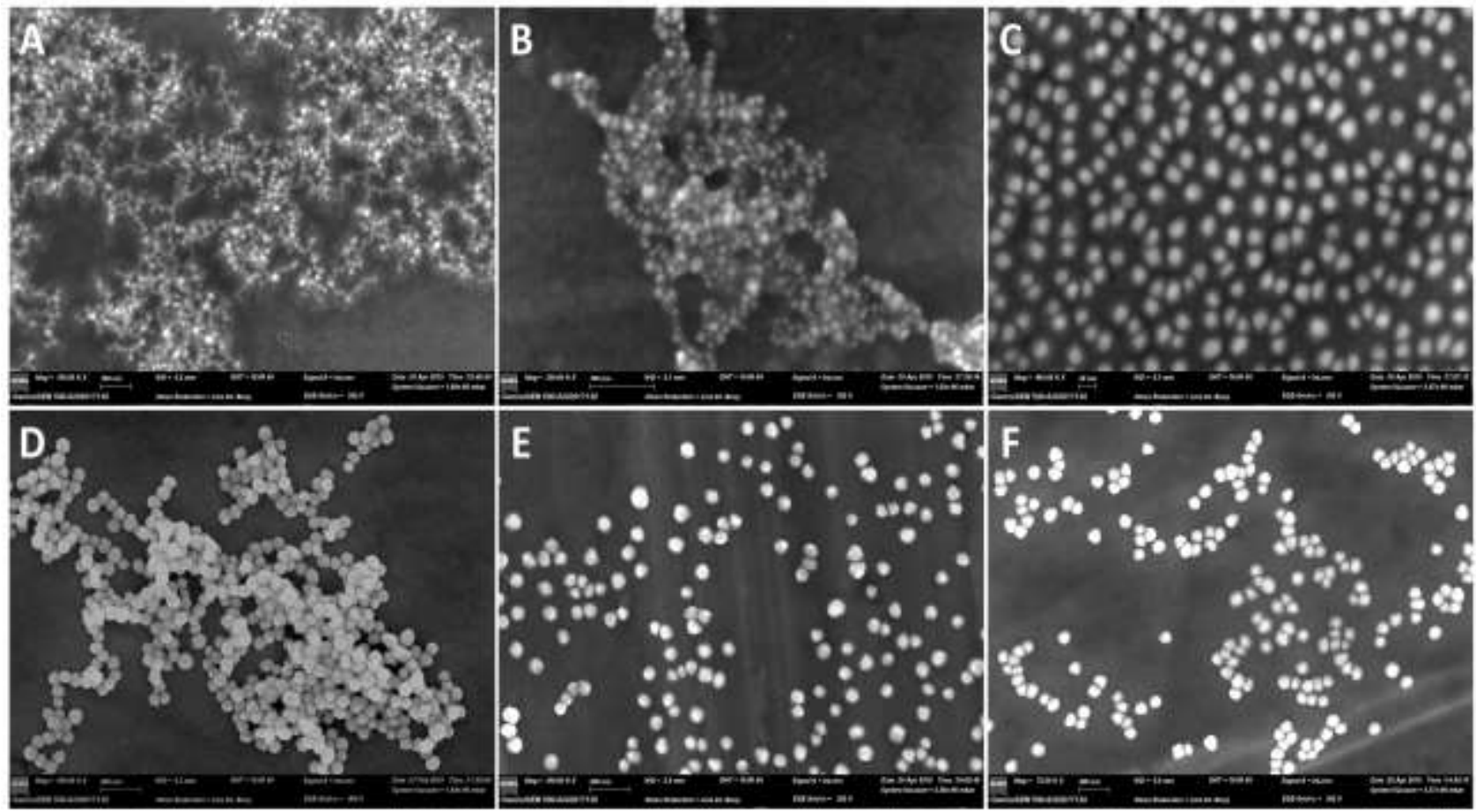

Figure 1. SEM images of synthesized gold nanoparticles. (A) AuNP20. (B) AuNP ${ }_{23}$-PEI. (C) AuNP 24 -PEG. (D) $\mathrm{AuNP}_{50}$. (E) AuNP 54 -PEI. (F) AuNP 56 -PEG

staining. The liver, the organ where nanomaterials accumulate the most, is also essential in nanotoxicity evaluations. Liver tissues were the most affected tissues after a 48 $\mathrm{h}$ exposure period (Figure 2). The hepatocytes and portal areas of the liver tissue had a regular appearance in the specimens within the control group (Figure $2 \mathrm{~A}$ ).

After such a short-term exposure period to low concentrations of AuNPs, minimal histological changes (e.g., slightly degenerated hepatocytes with hyperchromatic nuclei, low level of lymphocyte infiltration, minimal increase in the cell numbers of Kupffer, enlarged sinusoids) were observed in the liver tissues from specimens in the experimental groups compared to the control group (Figure $2 \mathrm{~B}, \mathrm{C}$ ). The microstructure of the liver tissue was similar to the control group in the AuNP groups containing PEI or PEG surface coatings (Figure $2 \mathrm{~B}_{2}, \mathrm{~B}_{3}, \mathrm{C}_{2}, \mathrm{C}_{3}$ ), although the observed changes did not depend on the AuNPs size. Liver parenchyma tissue was similar to normal, especially in specimens treated with the PEIcoated AuNP groups. The results were similar when considering liver groups exposed to high concentrations of AuNP groups (Figure 2 D, E). On the other hand, microstructural histological changes for the liver tissue were observed more clearly due to short-term (48 h) AuNPs exposure at high concentrations. Again, fewer cellular degenerations were observed in the AuNP groups with additional PEG or PEI functionalization (Figure $2 \mathrm{D}_{2}, \mathrm{D}_{3}, \mathrm{E}_{2}, \mathrm{E}_{3}$ ) than in the citrate-stabilized AuNP groups (Figure 2 $\mathrm{D}_{1}, \mathrm{E}_{1}$ ), although there were few size-related changes.

Microstructural histological changes observed in other organs (e.g., brain, kidney, and spleen) were relatively fewer than in the control groups after the short-term (48 h) AuNPs exposure period (Figure 3, 4, 5). Because of the bloodbrain barrier in the brain, no noticeable histological alterations were observed after the $48 \mathrm{~h}$ exposure period to AuNPs. The results were similar for both high 

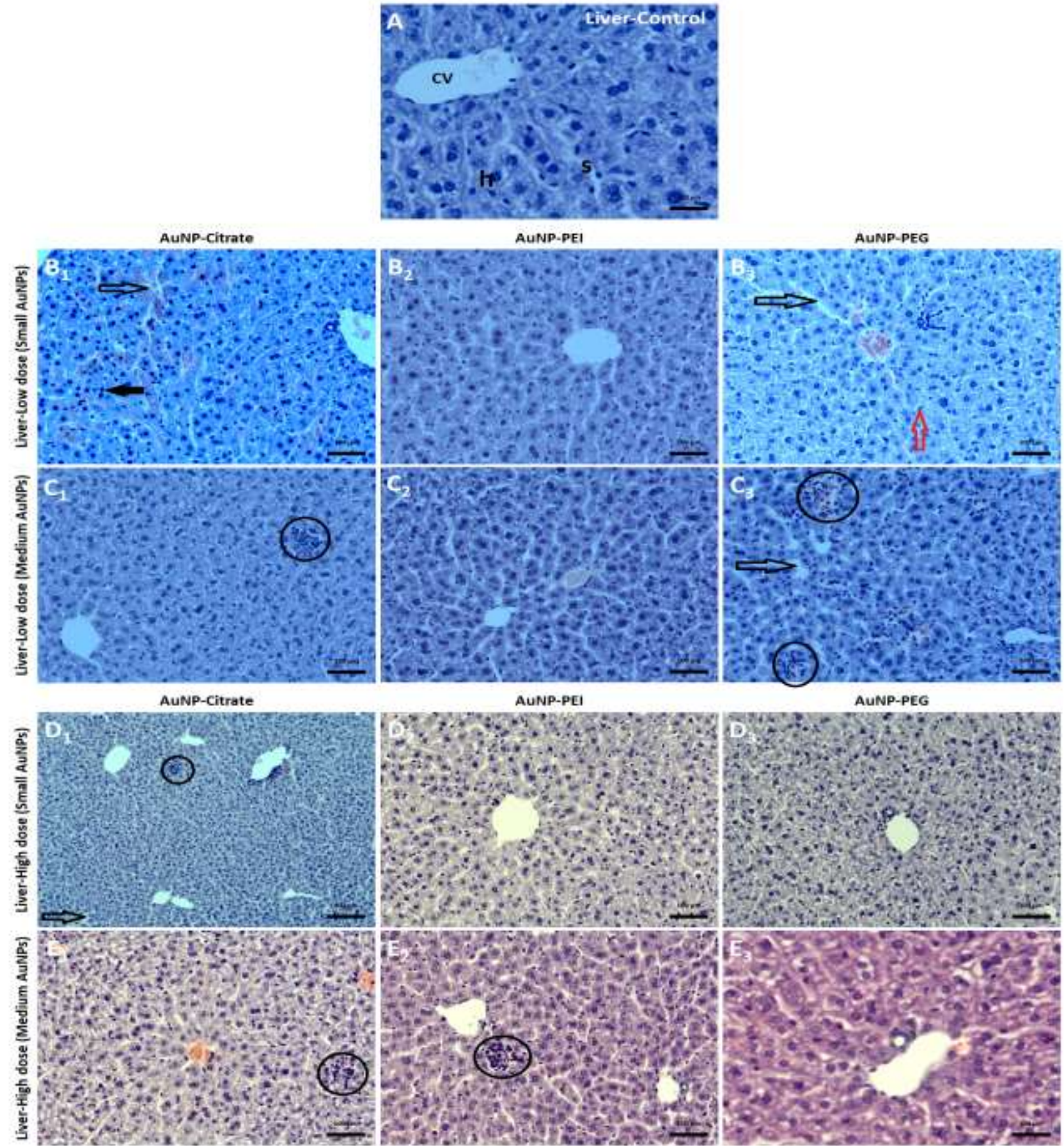

Figure 2. Histological evaluations of the AuNPs on the microstructural changes for the liver tissue in mice at $48 \mathrm{~h}$ after two different doses ( 0.5 and $5 \mathrm{mg} \mathrm{Au} / \mathrm{kg}$ animal weight) i.v. injection of gold nanoparticles. (A) Control. (Figure B, C) Low dose. (Figure D, E) High dose. $\left(\mathrm{B}_{1}\right),\left(\mathrm{D}_{1}\right) \mathrm{AuNP}_{20}$. $\left(\mathrm{B}_{2}\right),\left(\mathrm{D}_{2}\right) \mathrm{AuNP}_{23}-\mathrm{PEI} .\left(\mathrm{B}_{3}\right),\left(\mathrm{D}_{3}\right) \mathrm{AuNP}_{24-}$ PEG. $\left(C_{1}\right),\left(E_{1}\right)$ AuNP $50 .\left(C_{2}\right),\left(E_{2}\right)$ AuNP 54 -PEI. $\left(C_{3}\right),\left(E_{3}\right)$ AuNP 56 -PEG. (H\&E, 20× objective). Black fulled arrow: hyperchromatic nucleus of hepatocytes, black circle: lymphocyte infiltration, black empty arrow: enlarged sinusoids, red empty arrow: Kupffer cell, CV: central vein, S: Sinusoidal capillary, h: hepatocyte.

and low AuNPs concentrations. Healthy neuronal and glial cell morphologies and typical axonal and dendritic structures were observed in all AuNP groups (Figure 3).

No significant degenerations were observed in the kidney tissue from specimens from any of the AuNP groups exposed to low and high $\mathrm{Au}$ concentrations. The renal cortex, glomerulus, and tubular structures generally had a healthy morphology (Figure 4). In contrast, slightly degenerated glomerular structures and slightly enlarged tubules were observed in the citrate- 

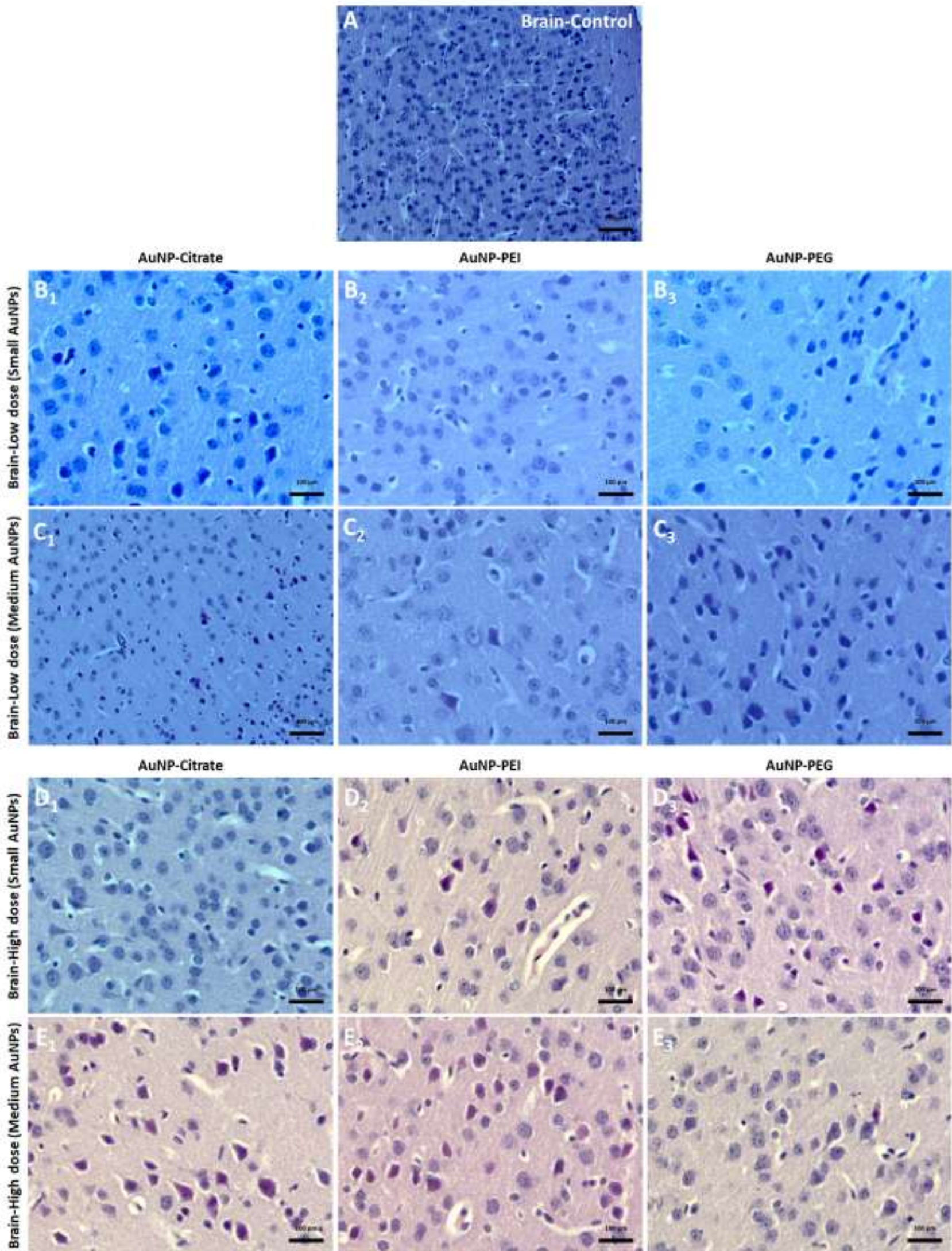

Figure 3. Histological evaluations of the AuNPs on the microstructural changes for the brain tissue in mice at $48 \mathrm{~h}$ after two different doses ( 0.5 and $5 \mathrm{mg} \mathrm{Au} / \mathrm{kg}$ animal weight) i.v. injection of gold nanoparticles. (A) Control. (Figure B, C) Low dose. (Figure D, E) High dose. $\left(\mathrm{B}_{1}\right)$, $\left(\mathrm{D}_{1}\right) \mathrm{AuNP}_{20}$. $\left(\mathrm{B}_{2}\right)$, $\left(\mathrm{D}_{2}\right) \mathrm{AuNP}_{23}-\mathrm{PEI}$. $\left(\mathrm{B}_{3}\right)$, $\left(\mathrm{D}_{3}\right)$ AuNP 24 -PEG. $\left(\mathrm{C}_{1}\right),\left(\mathrm{E}_{1}\right) \mathrm{AuNP}_{50}$. $\left(\mathrm{C}_{2}\right),\left(\mathrm{E}_{2}\right)$ AuNP 54 -PEI. $\left(\mathrm{C}_{3}\right),\left(\mathrm{E}_{3}\right)$ AuNP 56 -PEG. (H\&E, 40× objective). 

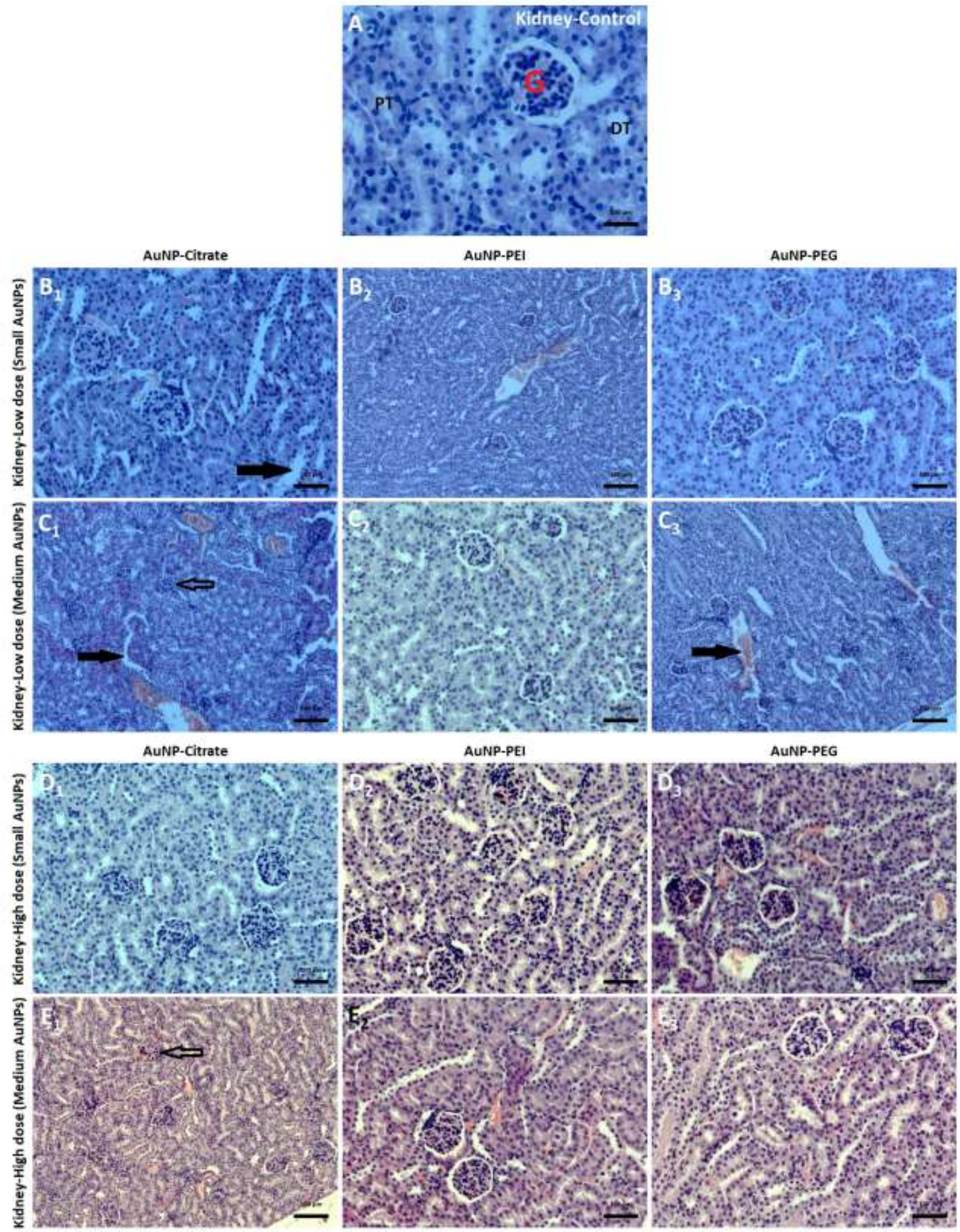

AUNP-PEG

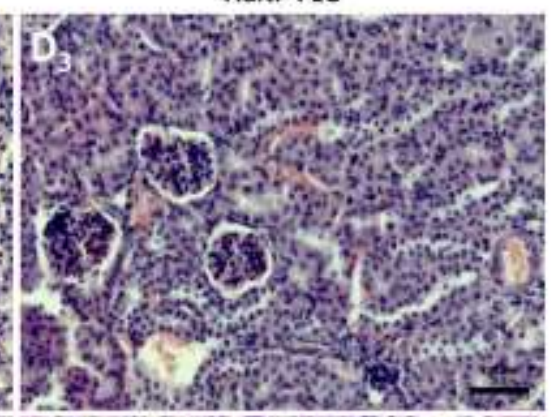

Figure 4. Histological evaluations of the AuNPs on the microstructural changes for the kidney tissue in mice at $48 \mathrm{~h}$ after two different doses ( $0.5 \mathrm{and} 5 \mathrm{mg} \mathrm{Au} / \mathrm{kg}$ animal weight) i.v. injection of gold nanoparticles. (A) Control. (Figure B, C) Low dose. (Figure D, E) High dose. $\left(B_{1}\right),\left(D_{1}\right) A_{u N P}$. $\left(B_{2}\right),\left(D_{2}\right)$ AuNP $23-P E I .\left(B_{3}\right),\left(D_{3}\right) A u N P_{24}$ PEG. $\left(C_{1}\right),\left(E_{1}\right)$ AuNP $50 .\left(C_{2}\right),\left(E_{2}\right)$ AuNP 54 -PEI. $\left(C_{3}\right),\left(E_{3}\right)$ AuNP56-PEG. (H\&E, 20× objective). G: Glomerular structure, DT: Distal tubule, PT: proximal tubule, black empty arrow: degenerated glomerular structures, black fulled arrow: enlarged tubules. 

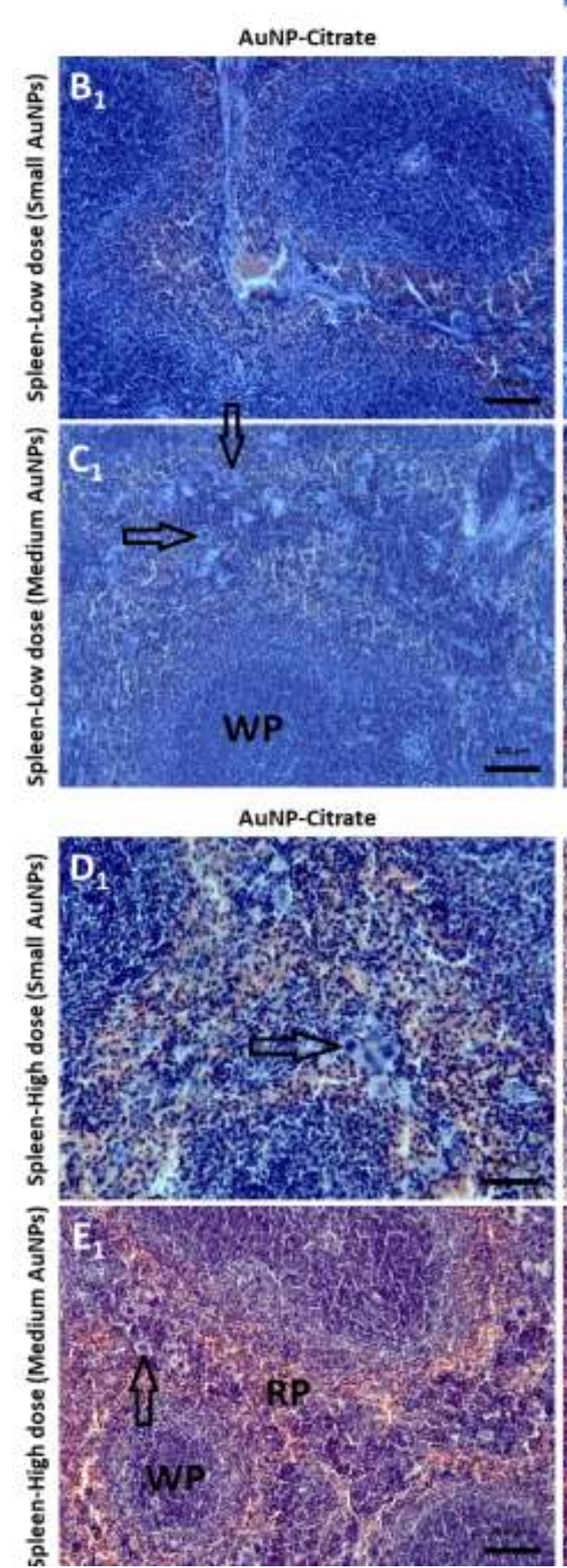

Figure 5. Histological evaluations of the AuNPs on the microstructural changes for the spleen tissue in mice at 48 $\mathrm{h}$ after two different doses (0.5 and $5 \mathrm{mg} \mathrm{Au} / \mathrm{kg}$ animal weight) i.v. injection of gold nanoparticles. (A) Control. (Figure B, C) Low dose. (Figure D, E) High dose. $\left(B_{1}\right),\left(D_{1}\right) A_{u N P}$. $\left(B_{2}\right),\left(D_{2}\right) A_{1} N_{23}-P E I .\left(B_{3}\right),\left(D_{3}\right) A_{u N P}{ }^{-}$ PEG. $\left(C_{1}\right),\left(E_{1}\right)$ AuNP $50 .\left(C_{2}\right),\left(E_{2}\right)$ AuNP 54 -PEI. $\left(C_{3}\right),\left(E_{3}\right) A_{4 N P}$-PEG. (H\&E, 10× objective). WP: White pulp, RP: Red pulp, black empty arrow: large macrophages.
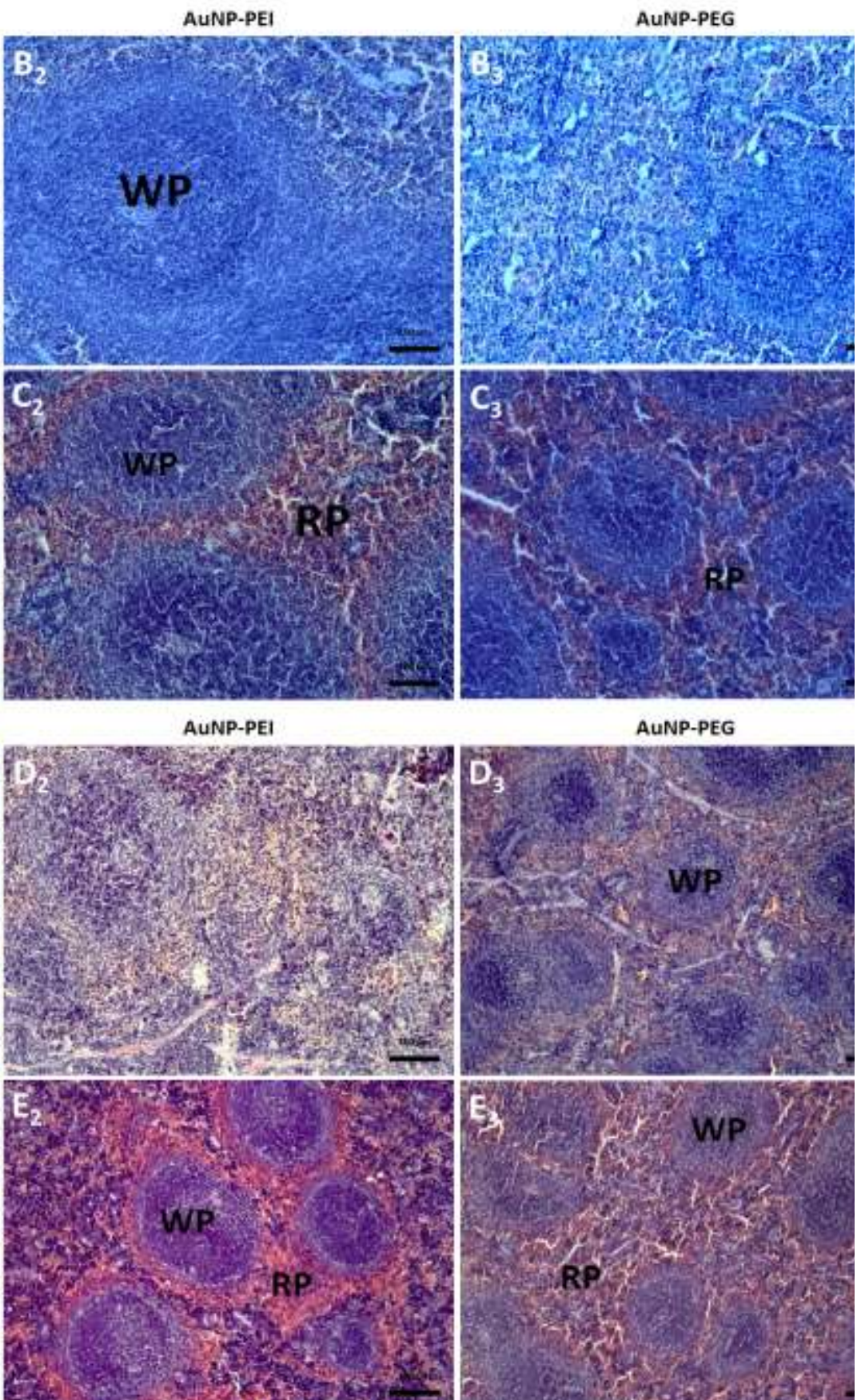
stabilized AuNP groups. No histological changes were observed depending on the particle sizes. The spleen is another vital organ after the liver in terms of nanotoxicological evaluations. White and red pulp structures with regular appearances were generally observed (Figure 5) after the exposure period to low AuNPs concentrations. Lymphoid follicles surrounded by large macrophages were observed, especially in the citrate-stabilized AuNP 50 group (Figure $5 \mathrm{C}_{1}$ ). After exposure to high AuNP concentrations in the AuNP groups without additional surface coating, lymphoid follicles were surrounded by large macrophages (Figure $5 \mathrm{D}_{1}, \mathrm{E}_{1}$ ). In contrast, in the groups of AuNPs containing PEI and PEG surface coating, spleen tissue morphologies were evaluated as normal (Figure $5 \mathrm{D}_{2}, \mathrm{D}_{3}, \mathrm{E}_{2}, \mathrm{E}_{3}$ ).

\section{Ultrastructural histological evaluations of the liver}

TEM analysis was performed to reveal the effects of different AuNP groups on the ultrastructural changes in the liver of the mice in more detail on the 14th day after a single high dose $(5 \mathrm{mg} \mathrm{Au} / \mathrm{kg}$ ) intravenous injection of AuNPs (Figure 6). Cellular structures were evaluated as normal and healthy in the control group (Figure 6A). In the AuNP groups, mainly in the medium-sized AuNPs group without additional surface coating, apparent cellular changes (e.g., enlarged cisternae, degraded granular or agranular endoplasmic reticulum, deformed nuclei, mitochondria) were observed after the long exposure period (Figure 6B, E). Although slightly enlarged cisterna structures were observed in the AuNP groups coated with PEG and PEI, the morphology of the hepatocyte cells was generally healthy (Figure 6C, D, F, $\mathrm{G})$. AuNPs clusters were observed again in the cytoplasmic regions and within the cell nuclei (as indicated by arrows).

\section{Discussion}

Highly monodispersed and stable AuNPs were synthesized using the modified Turkevich synthesis method and the seeding-growth method. The PEI and PEG surface functionalization prevented the aggregation of the particles in the aqueous phase and made them more stable. The chemical surface and charge of the particles were also changed by the optimal and successful surface modifications of the AuNPs coated with PEI and PEG. With such features, the behavior of the particles in the biological environment was affected. There was a significant positive increase in the zeta potentials of the particles, especially after the PEI coating. When AuNPs are positively charged, they can easily and directly interact with negatively charged molecules (e.g., RNA and DNA). The advantage of effective potential applications for DNA delivery or siRNA-based gene silencing studies is offered with such an interaction. In the literature, researchers have shown that AuNPs with PEI surface coating are highly effective as gene silencing agents by conjugating with siRNA [22, 23].

Foreign molecules in the bloodstream are recognized by reticuloendothelial system (RES) components and are inactivated by being transported to the liver and spleen in in vivo biological environments. In particular, the liver is the organ where the nanoparticles entering the systemic circulation accumulate more frequently. Therefore, the liver is a vital organ that should always be considered in in vivo nanotoxicological evaluations [24]. Also, the spleen is an essential organ in the immune system and lymphoid maturation. With the assessment of liver and spleen cells, several toxic effects of nanoparticles are better understood. Significant level accumulation occurs in the liver and spleen, followed by the 


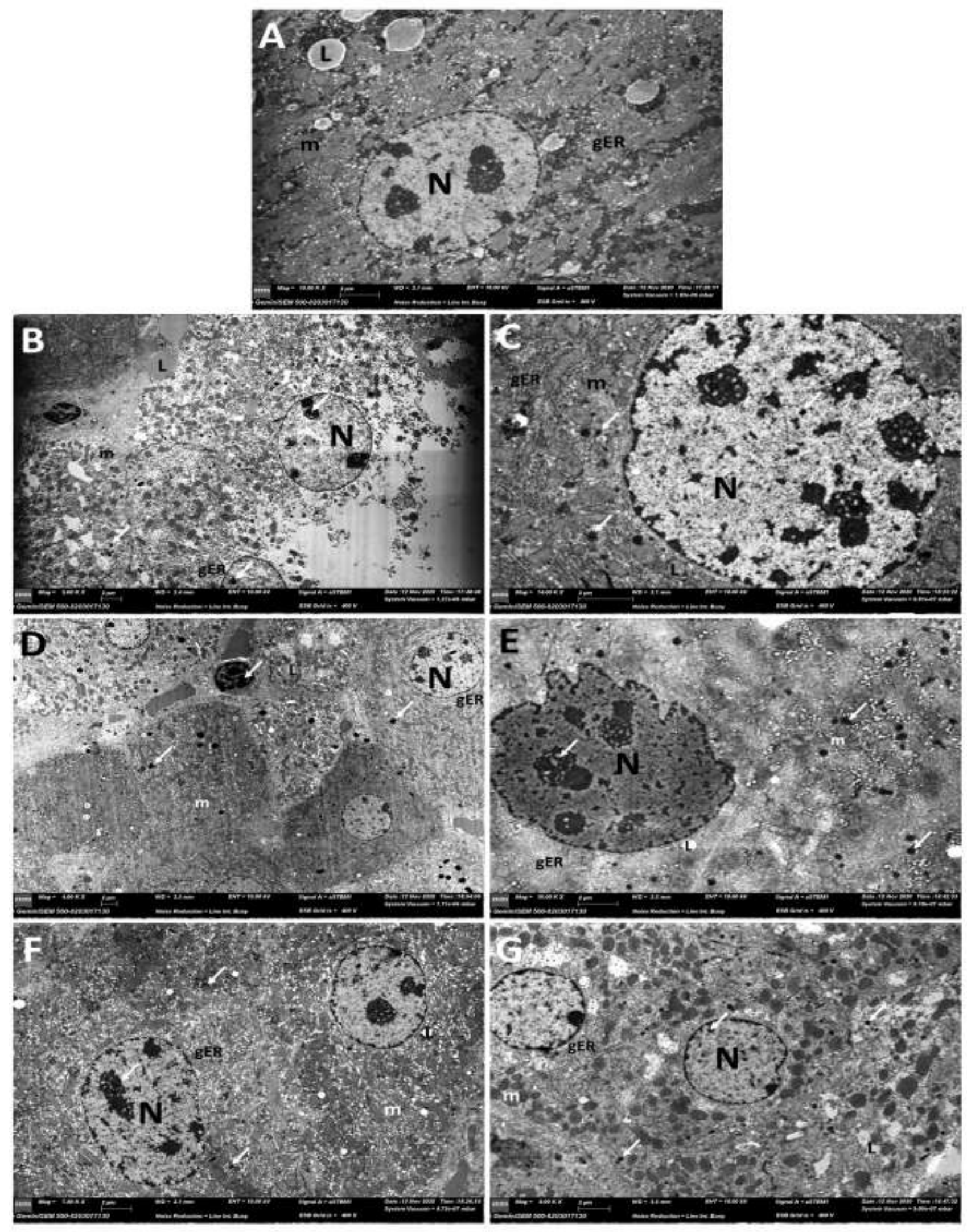

Figure 6. Ultrastructral histological evaluation of AuNPs using TEM for the liver tissue in mice on day 14 after a single dose (5 mg Au/kg animal weight) i.v. injection of gold nanoparticles. (A) Control. (B) AuNP 20 . (C) $\mathrm{AuNP}_{23^{-}}$

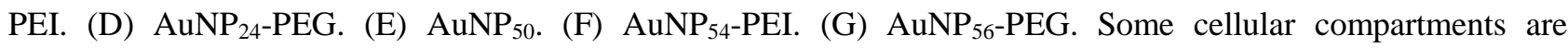
represented by letters: N: Nucleus of the hepatocyte, L: Lipid droplet, m: Mitochondria, gER: Granular endoplasmic reticulum. Arrows show the gold nanoparticle aggregates localized in the various cellular compartments and the cell nucleus. 
kidneys and circulatory system after intestinal nanoparticle absorption [25].

The liver tissue was the most toxicologically affected during the $48 \mathrm{~h}$ period according to our $H \& E$ staining results after two different doses of AuNPs exposure in mice. Although significant histological alterations were not observed depending on AuNPs size, the microstructure of the liver tissue was considered to be more similar to the control group in specimens treated with AuNPs containing PEI or PEG surface modification. Abdelhalim et al. showed that smaller particles cause more toxic effects (e.g., increase in the number of sinusoidal Kupffer cells, fatty changes in swollen hepatocytes, necrosis) in the liver of the rats after the injection of AuNPs with different diameters [18]. Histological changes in other organs were relatively less frequent when compared to liver tissues. Because of the presence of the blood-brain barrier, no noticeable changes were observed in the brain. No significant cellular degenerations in the kidney tissue were observed for any AuNP group exposed to low and high $\mathrm{Au}$ concentrations.

On the other hand, slightly degenerated glomerular structures and slightly enlarged tubules were observed in the AuNP-citrate groups. Ma et al. observed collagen accumulation in the renal parenchyma after administering AuNPs with different diameters and concentrations to mice, especially at high concentrations [26]. The spleen is another vital organ after the liver in terms of nanotoxicological considerations. After exposure to high AuNPs concentrations, lymphoid follicles surrounded by large macrophages were observed in the tissues of individuals treated with AuNP-citrate groups. Since the spleen is a critical lymphoid organ, this inflammatory physiological response depends on the exposure of these particles. The PEI and PEG surface modifications generally increased the biocompatibility of the AuNPs. According to previously published results, different surface charges of AuNPs caused by changes in the chemical surface of the AuNPs can also trigger changes in liver and spleen tissues [27].

Apparent cellular changes and degenerations were observed after a long exposure period in the AuNP-citrate groups, according to our TEM analysis results. Although slight cellular changes were observed in the AuNP groups modified with PEG or PEI, the morphology of the hepatocyte cells was generally expected. We were allowed by TEM analysis of liver tissue to evaluate the cellular localization of the AuNPs. AuNPs clusters were observed in the cytoplasmic regions and cell nuclei, especially in surface-modified AuNP groups. Fraga et al. [28] showed that nanoparticles localized predominantly as endosomes in Kupffer cells after injection of $20 \mathrm{~nm}$ diameter citrate- and CALNN-pentapeptide-coated AuNPs into rats. Those researchers reported that they could not observe nanoparticles in the cytosol or nucleus of hepatocyte cells [28].

It is essential for nanoparticles to remain in sufficient quantities in the cytoplasm and nucleus, escaping from endosomal and lysosomal pathways without exocytosis. Additional surface modifications are needed to allow nanoparticles to escape through these pathways and enter the cell nucleus. Thus, a variety of potential nanotherapeutic applications can be implemented more effectively. Nanoparticles must also remain in organs for the required time and amount without causing toxic effects to have sufficient impact on cells for potential biomedical purposes. 


\section{Conclusions}

In summary, we performed a systematic study to understand the histological effects of AuNPs with different surface coatings (PEI or PEG) and sizes (AuNP 20 and $\left.\mathrm{AuNP}_{50}\right)$ in mice. Stable and highly monodispersed AuNPs were synthesized successfully. It has been concluded that the surface coating of AuNPs is a more decisive parameter than size in terms of in vivo histological toxicity. Histologically, it was observed that the liver was the most affected organ. PEI and PEG surface modifications increased the biocompatibility of the AuNPs. Stability, biocompatibility, and AuNP surface coating are critical parameters for potential nanoteranostic applications.

Acknowledgments: The authors would like to thank the Scientific and Technological Research Council of Turkey (Grant no: 217S135) for providing financial support for this project.

Funding: The Scientific and Technological Research Council of Turkey (TUBITAK) (Grant no: 217S135).

Conflict of Interest: The authors declare that they have no conflict of interest.

Ethical statement: The animal procedures were performed under the Istanbul Medipol University Institutional Animal Care and Use Committee (IMU-HADYEK, Approval date/number: May 18, 2017/21).

Open Access Statement: This is an open access journal which means that all content is freely available without charge to the user or his/her institution under the terms of the Creative Commons Attribution Non-Commercial License

(https://creativecommons.org/licenses/by/4.0/). Users are allowed to read, download, copy, distribute, print, search, or link to the full texts of the articles, without asking prior permission from the publisher or the author.

Copyright (c) 2021: Author (s).

\section{References}

[1] Boisselier E, Astruc D. Gold nanoparticles in nanomedicine: preparations, imaging, diagnostics, therapies and toxicity. Chemical Society Reviews. 2009; 38 (6):1759-82.

[2] Kim CS, Tonga GY, Solfiell D, et al. Inorganic nanosystems for therapeutic delivery: Status and prospects. Adv Drug Deliver Rev. 2013; 65 (1):93-99.

[3] Camilo DE, Miyazaki CM, Shimizu FM, et al. Improving direct immunoassay response by layer-by-layer films of gold nanoparticles - Antibody conjugate towards label-free detection. Mater Sci Eng C Mater Biol Appl. 2019; 102:315-23.

[4] Hamdy ME, Del Carlo M, Hussein HA, et al. Development of gold nanoparticles biosensor for ultrasensitive diagnosis of foot and mouth disease virus. J Nanobiotechnology. 2018; 16 (1):48.

[5] Betzer O, Perets N, Angel A, et al. In Vivo Neuroimaging of Exosomes Using Gold Nanoparticles. ACS Nano. 2017; 11 (11):10883-93.

[6] Ruttala HB, Ramasamy T, Poudel BK, et al. Multi-responsive albumin-lonidamine conjugated hybridized gold nanoparticle as a combined photothermal-chemotherapy for synergistic tumor ablation. Acta Biomater. 2020; 101:531-43.

[7] Wu D, Wang H, Hou X, et al. Effects of gold core size on regulating the performance of doxorubicin-conjugated gold nanoparticles. Nano Research. 2018; 11 (6):3396-410.

[8] Cebrian V, Martin-Saavedra F, Yague C, et al. Size-dependent transfection efficiency of PEI-coated gold nanoparticles. Acta Biomater. 2011; 7 (10):3645-55. 
[9] Ghosh R, Singh LC, Shohet JM, et al. A gold nanoparticle platform for the delivery of functional microRNAs into cancer cells. Biomaterials. 2013; 34 (3):807-16.

[10] Fratoddi I, Venditti I, Cametti C, et al. How toxic are gold nanoparticles? The state-ofthe-art. Nano Research. 2015; 8 (6):1771-99.

[11]Chompoosor A, Saha K, Ghosh PS, et al. The role of surface functionality on acute cytotoxicity, ROS generation and DNA damage by cationic gold nanoparticles. Small. 2010; 6 (20):2246-49.

[12]Cui W, Li J, Zhang Y, et al. Effects of aggregation and the surface properties of gold nanoparticles on cytotoxicity and cell growth. Nanomedicine. 2012; 8 (1):46-53.

[13] Coradeghini R, Gioria S, Garcia CP, et al. Size-dependent toxicity and cell interaction mechanisms of gold nanoparticles on mouse fibroblasts. Toxicol Lett. 2013; 217 (3):20516.

[14] Brandenberger C, Muhlfeld C, Ali Z, et al. Quantitative evaluation of cellular uptake and trafficking of plain and polyethylene glycol-coated gold nanoparticles. Small. 2010; 6 (15):1669-78.

[15]Zhao F, Zhao Y, Liu Y, et al. Cellular uptake, intracellular trafficking, and cytotoxicity of nanomaterials. Small. 2011; 7 (10):1322-37.

[16] Wang X, Hu X, Li J, et al. Influence of cell size on cellular uptake of gold nanoparticles. Biomater Sci. 2016; 4 (6):970-78.

[17] Shahbazi R, Ozcicek I, Ozturk G, et al. Functionalized gold nanoparticles manifested as potent carriers for nucleolar targeting. Nanotechnology. 2017; 28 (2).

[18] Abdelhalim MAK, Jarrar BM. Histological alterations in the liver of rats induced by different gold nanoparticle sizes, doses and exposure duration. J Nanobiotechnol. 2012; 10.
[19] Khlebtsov N, Dykman L. Biodistribution and toxicity of engineered gold nanoparticles: a review of in vitro and in vivo studies. Chem Soc Rev. 2011; 40 (3):1647-71.

[20] Turkevich J, Stevenson PC, Hillier J. A Study of the Nucleation and Growth Processes in the Synthesis of Colloidal Gold. Discuss Faraday Soc. 1951 (11):55-\&.

[21] Perrault SD, Chan WCW. Synthesis and Surface Modification of Highly Monodispersed, Spherical Gold Nanoparticles of 50-200 nm. J Am Chem Soc. 2009; 131 (47):17042-+.

[22] Song WJ, Du JZ, Sun TM, et al. Gold nanoparticles capped with polyethyleneimine for enhanced siRNA delivery. Small. 2010; 6 (2):239-46.

[23] Shahbazi R, Asik E, Kahraman N, et al. Modified gold-based siRNA nanotherapeutics for targeted therapy of triple-negative breast cancer. Nanomedicine. 2017; 12 (16):1961-73.

[24]Lasagna-Reeves C, Gonzalez-Romero D, Barria MA, et al. Bioaccumulation and toxicity of gold nanoparticles after repeated administration in mice. Biochem Bioph Res Co. 2010; 393 (4):649-55.

[25] Ganguly P, Breen A, Pillai SC. Toxicity of Nanomaterials: Exposure, Pathways, Assessment, and Recent Advances. Acs Biomater Sci Eng. 2018;4(7):2237-75.

[26] Ma X, Sun J, Zhong L, et al. Evaluation of Turning-Sized Gold Nanoparticles on Cellular Adhesion by Golgi Disruption in Vitro and in Vivo. Nano Lett. 2019; 19 (12):8476-87.

[27]Elci SG, Jiang Y, Yan B, et al. Surface Charge Controls the Suborgan Biodistributions of Gold Nanoparticles. ACS Nano. 2016; 10 (5):5536-42. 
[28]Fraga S, Brandao A, Soares ME, et al. Shortand long-term distribution and toxicity of gold nanoparticles in the rat after a singledose intravenous administration.

Nanomedicine. 2014; 10 (8):1757-66. 